\title{
Efeitos de Regras e Autorregras nos relatos de mudança comportamental na Terapia Analítica Comportamental
}

\author{
Effects of rules and self-rule on Analytical-Behavioral Therapy behavior \\ change reports
Efectos de Reglas y Auto reglas en los relatos de cambio comportamental en la Terapia Analítica-Conductual

\author{
Antonio de Pádua Azevedo Silva', Prof. Dr. Carlos Augusto de Medeiros ${ }^{2}$
}

\begin{abstract}
[1] Centro Universitário de Brasília - UniCEUB I Título abreviado: Regras e autorregras na clínica comportamental I Endereço para correspondência: Coordenação do Mestrado em Psicologia, Secretaria da Pós-graduação Stricto Sensu, SEPN 707/907 - bloco 3 - térreo - campus do UniCEUB - Brasília/DF 70790-075 I Email: medeiros.c.a@gmail.com I doi: 10-18761/PAC.TAC.2019.013 I Notas: Financiamento Próprio. Gostaríamos de agradecer às terapeutizandas que participaram de estudo. Ao Centro Universitário de Brasília - UniCEUB e ao Centro de Formação Profissional do UniCEUB por fornecerem o apoio institucional para a realização da pesquisa. Não há conflito de interesses relativos à execução da pesquisa e à submissão do manuscrito à revista Perspectivas em Análise do Comportamento. O projeto de pesquisa concernente ao manuscrito foi aprovado pelo CEP - UniCEUB, parecer número 608/11, processo: CAAE 0307/11.
\end{abstract}

Resumo: O presente estudo avaliou o relato de seguimento de regras e autorregras no contexto clínico. Para tanto foi realizada uma pesquisa com duas terapeutizandas e um terapeuta estagiário em uma clínica escola de Brasília. O terapeuta em sessões iniciais do processo terapêutico emitiu três regras para cada cliente e, aplicou o procedimento de questionamento reflexivo para que as duas participantes formulassem três autorregras em contextos específicos de suas vidas. Os questionamentos reflexivos consistem em conjuntos de questões abertas encadeadas de forma lógica, formulados pelo terapeuta com a função de evocar autorregras. Em seguida, o conteúdo das sessões subsequentes foi analisado de modo a identificar que tipo de regras foi seguido com maior frequência durante a terapia com base nos relatos verbais das participantes, considerando as oportunidades de seguimentos. Os relatos de seguimento das autorregras geradas por questionamento reflexivo foram mais numerosos para as duas participantes em todos os contextos de vida. Com base nos resultados encontrados nessa pesquisa, a despeito de limitações de controle experimental, foi corroborada a hipótese de que ouvintes tendem as seguir mais as autorregras que as regras emitidas por outros falantes.

Palavras-chave: Regras; Autorregras; Terapia Analítica-Comportamental; Questionamento Reflexivo. 
Abstract: The present study evaluated reports of rules and self-rules following in the clinical context. The research was conducted with two patients and one therapist in a clinic school in Brasilia. At initial sessions, the therapist emitted three rules for each patient and applied the reflexive questioning procedure in order to evocate three self-rules formulation by participants in specific contexts of their lives. The reflexive questioning procedure consist of sets of open questions chained in a logical way, formulated by the therapist with the function of evoking self-rules. Subsequent session content was then analyzed to identify which type of rules were most frequently followed during therapy based on participants' verbal reports. Reports of follow-up rules generated by reflexive questioning were more frequent for the two participants in all life contexts. Based on the results found in this research, despite the limitations of experimental control, it was corroborated the hypothesis that listeners tend to follow more self-rules than the rules presented by other speakers.

Keywords: Rules; Self-Rules; Analytical-Behavioral Therapy; Reflexive Questioning Procedure.

Resumen: El presente estudio evaluó relatos de seguimiento reglas y auto reglas en el contexto clínico. La investigación se realizó con dos pacientes y un terapeuta en una clínica escuela en Brasilia. En las sesiones iniciales, el terapeuta emitió tres reglas para cada paciente y aplicó el procedimiento de cuestionamientos reflexivos para evocar la formulación de tres auto-reglas por parte de los participantes en contextos específicos de sus vidas. El procedimiento de cuestionamientos reflexivos consiste en conjuntos de preguntas abiertas encadenadas de una manera lógica, formuladas por el terapeuta con la función de evocar auto reglas. Posteriormente, se analizó el contenido de la sesión para identificar qué tipo de reglas se seguían con más frecuencia durante la terapia según los relatos de los participantes. Los relatos de seguimiento de las reglas generadas por el cuestionamiento reflexivo fueron más frecuentes para los dos participantes en todos los contextos de la vida. Con base en los resultados encontrados en esta investigación, a pesar de las limitaciones del control experimental, se corroboró la hipótesis de que los oyentes tienden a seguir más auto reglas que las reglas presentadas por otros oradores.

Palabras-clave: Reglas; Auto reglas; Terapia Analítica-Conductual; Procedimiento de Cuestionamiento Reflexivo. 
$\mathrm{Na}$ medida em que o terapeuta tem mínimo acesso aos eventos que ocorrem fora da terapia, o seu poder de intervenção sobre os comportamentos de relevância clínica é limitado (Skinner, 1989). Ainda que parte dos comportamentos alvo ocorram na relação terapêutica (Ferster, 1972; Kohlenberg \& Tsai, 1991), sendo passíveis observação e intervenção direta, aqueles comportamentos que ocorrem fora da sessão são inacessíveis ao terapeuta. Em decorrência disso, as regras, definidas como descrições verbais de contingências, as quais podem afetar o comportamento do ouvinte (Baum, 2005/2006; Matos, 2001; Skinner, 1969; 1974), adquirem um papel fundamental na terapia (Medeiros, 2010; 2018; Skinner, 1989).

Há toda uma controvérsia acerca da definição de regras e de comportamento governado por regras em Análise do Comportamento (Hayes \& Hayes, 1989; Blakely \& Schlinger, 1987; Schlinger \& Blakely, 1987; Cerutti, 1989; Hayes, Zettle, \& Rosenfarb, 1989; Zettle \& Hayes, 1982). Regras podem ser definidas a partir da topografia, se constituindo no produto da resposta verbal de um falante que contem explícita ou implicitamente descrições de relações entre um comportamento e suas consequências em determinadas ocasiões, ainda que, raramente contenha todos os elementos da contingência. Por exemplo, a regra, "se você não tem dinheiro para pagar terapia, procure uma clínica escola", apenas implicitamente informa o ouvinte acerca da consequência do comportamento de procurar uma clínica escola. Daí resulta um desafio teórico e empírico de explicar como as regras controlam o comportamento do ouvinte. Esse é uma discussão da definição funcional de regras. Skinner (1969) define regras como estímulos discriminativos que especificam uma contingência. Porém, de acordo com Zettle e Hayes (1982), Skinner não explicita satisfatoriamente o que quis dizer com "especificam", o que abriu o debate acerca de como regras controlam o comportamento do ouvinte. Sendo assim, a própria função de regras como estímulo discriminativo tem sido questionada, de modo que as regras, segundo Blakely e Schlinger (1987) e Schlinger e Blakely (1987) poderiam funcionar como estímulos alteradores de função ou mesmo operações estabelecedoras mais do que meramente estímulos discriminativos.
Diz-se que um comportamento é governado por regras, de acordo com Albuquerque e Paracampo (2010), quando demonstra-se que o comportamento está de acordo regra independentemente de suas consequências. Por outro lado, o comportamento é controlado pela contingência quando sua frequência é controlada pelas suas consequências imediatas. Na maioria dos casos, o comportamento precedido por uma regra fica sob o controle de uma interação entre regras e consequências, a não ser que o seguimento da regra impeça o contato com a contingência como no Experimento 2 de Galizio (1979). Para verificar se o comportamento está sob o controle de uma regra ou das contingências, testes em experimentos devem ser conduzidos, modificando-se a contingência mantendo-se a regra constante (e.g., Galizio, 1979) ou mudando-se a regra e mantendo-se a contingência constante (e.g., Albuquerque \& Silva, 2006). Quando o comportamento não muda quando modifica-se a contingência ou quando o comportamento muda a partir de uma nova regra, mesmo a contingência sendo mantida constante, classifica-se tal comportamento como insensível às contingências (Albuquerque \& Paracampo, 2010).

A insensibilidade comportamental tem sido um dos fenômenos mais extensamente investigados e documentados em Análise Experimental do Comportamento (Abreu-Rodrigues \& SanbioHeck, 2004; Albuquerque \& Paracampo, 2010; Meyer, 2005; Paracampo \& Albuquerque, 2005). Alguns fatores que afetam o controle do comportamento por regras foram investigados empiricamente, como o nível de contato com a discrepância entre as regras e a contingência (Galizio, 1979; Paracampo \& Albuquerque, 2004), o histórico de seguimento de regras congruentes e discrepantes (Albuquerque, Souza, Matos, \& Paracampo, 2003; Albuquerque, Matos, Souza, \& Paracampo, 2004); o esquema de reforçamento em vigor na contingência descrita na regra (Oliveira \& Albuquerque, 2007); a presença de perguntas sobre as contingências (Albuquerque \& Silva, 2006; Albuquerque, Paracampo, Matsuo, \& Mescouto, 2013; Albuquerque, Silva, \& Paracampo, 2014); as propriedades formais da regra (Albuquerque \& Ferreira, 2001; Albuquerque, Mescouto, \& Paracampo, 2011); o monitoramento pelo falante do seguimento ou não da regra discrepante (Barret, 
Deitz, Gaydos, \& Quinn, 1987; Kroger-Costa \& Abreu-Rodrigues, 2012) e a apresentação de consequências sociais ao seguimento de regras discrepantes (Monteles, Paracampo \& Albuquerque, 2006), por exemplo.

Conforme discutido por Abreu-Rodrigues e Sanbio-Heck (2004), Guedes (1993; 1997), Medeiros (2002a; 2002b; 2010; 2018); Medeiros e Medeiros (2012) Meyer (2005) e Poppen (1989), uma parcela considerável dos comportamentos alvo do terapeutizando é controlada por regras que nem sempre descrevem de modo acurado e preciso às contingências que serviram de ocasião para a sua formulação. Em decorrência disso, comportamentos alvo a enfraquecer (i.e., aqueles cuja intervenção tem como objetivo reduzir de frequência, Medeiros \& Medeiros, 2012) sob o controle de regras apresentam frequência elevada mesmo resultando em não reforçamento, reforçamento infrequente e de baixa magnitude, ou mesmo, na apresentação de estímulos aversivos. O mesmo vale para os comportamentos a fortalecer, os quais seriam passíveis de reforçamento, ainda que intermitente, cuja baixa frequência pode estar relacionada ao controle por regras.

Fora a insensibilidade às contingências, muitos terapeutizandos não descrevem as variáveis que controlam os seus comportamentos (Poppen, 1989), o que, de acordo com Skinner (1953), diminui a probabilidade de atuarem sobre o próprio comportamento ao modificarem diretamente as variáveis que o determinam. Em outras palavras, há a ausência de autoconhecimento, cujo estabelecimento acaba sendo uma das metas da Terapia Analítico Comportamental - TAC (RodriguesRibeiro, 2001). Segundo Medeiros (2010), o autoconhecimento envolve a emissão de autorregras que, de acordo com Meyer (2005), se constituem em descrições verbais de contingências controladoras do próprio comportamento do falante.

As regras, em decorrência dos fatores listados, são fundamentais à clínica, seja pela modificação de regras discrepantes, seja por consistirem na descrição acurada das variáveis de controle dos comportamentos alvo dos terapeutizando, ou mesmo, como forma de atuar diretamente sobre o ambiente dos terapeutizandos. De acordo com Medeiros $(2010 ; 2018)$ e Medeiros e Medeiros
(2018), a emissão de regras pelos terapeutas parece ser a primeira alternativa como modo de intervenção em clínica. De fato, como observado nos levantamentos feitos por Falcão (2011), Meyer e Donadone (2002), Donadone e Meyer (2005), Donadone e Meyer (2017), Zamignani e Meyer (2017), a emissão de regras por terapeutas, em praticamente todas as vertentes de terapia analítica comportamental, experientes ou não, é corriqueira na TAC. As terapias comportamentais, independentemente da onda a que pertencem, se constituem em modelos diretivos de terapia, principalmente em decorrência da emissão de regras pelos terapeutas como forma de intervenção em contraposição às terapias humanistas e psicodinâmicas (Donadone \& Meyer, 2005; 2017).

O estudo de Falcão (2011) constatou que a emissão de regras por terapeutas de orientação analítico comportamentais e cognitivo comportamentais é frequente de modo a permitir constatar que tal prática se constitui uma das características dessas duas abordagens clínicas. Falcão (2011) realizou um estudo de meta-análise para verificar as condutas de terapeutas que se intitulavam analítico-comportamentais e cognitivos comportamentais com base em 15 diálogos transcritos de sessões de terapia em estudos de caso publicados na literatura nacional. As categorias utilizadas por Falcão foram: emissão de regras; solicitação de justificativas para o comportamento com o uso de perguntas iniciadas por "por que"?; apresentação de reforçadores positivos naturais e arbitrários; apresentação de estímulos aversivos; uso de perguntas fechadas; uso de perguntas abertas e outras verbalizações. Falcão identificou que houve a emissão de regras em mais de $90 \%$ dos diálogos analisados e que a emissão de regras consistiu em $30 \%$ das falas apresentadas. Também chamou a atenção a frequência elevada de apresentação de estímulos aversivos e a presença de reforçamento arbitrário em quase 100\% dos diálogos. Com base nesses resultados, Falcão concluiu o caráter diretivo da TAC e da Terapia Cognitivo Comportamental - TCC praticada no país com base nos estudos de caso publicados até 2011 .

O estudo de Meyer e Donandone (2002) também investigou a frequência de emissão de regras (i.e., orientações) por três terapeuta experientes, um intitulando-se behaviorista radical e os outros 
dois terapeutas intitulando-se comportamentais-cognitivos. Foram analisadas transcrições de registros de áudio de três sessões de três clientes de cada um dos três terapeutas participantes que não fossem as sessões iniciais. Para as autoras, as orientações são consideradas tipos de regras, as quais foram subdivididas em quatro categorias: orientações para ações específicas; orientações genéricas; orientações para reflexões e orientações para tarefas (e.g., deveres de casa). De acordo com a definição de regras utilizada por Falcão (2011), as orientações para reflexões e para tarefas não contariam como regras. Entretanto, a devolução de análise funcionais, ou interpretações, de acordo com a classificação de Zamignani e Meyer (2017), contaria como regra para Falcão, mas não foram incluídas como orientações por Meyer e Donadone (2002). As autoras encontram uma baixa incidência de orientações por parte dos terapeutas pesquisados em relação às falas totais das sessões, cujos tipos de orientações não variaram de modo sistemático em função de clientes, terapeutas e abordagem. As diferenças metodológicas e conceituais podem ser responsáveis pelas diferenças encontradas entre os estudos de Falcão (2011) e Meyer e Donadone (2002).

Já o estudo de Donadone e Meyer (2005), que utilizou metodologia similar à de Meyer e Donadone (2002), comparou a frequência de orientações e auto-orientações (i.e., quando o cliente emite uma autorregra ao longo da sessão) em função do nível de experiência dos terapeutas. Além disso, Donadone e Meyer (2005) analisaram uma amostra maior de sessões, sendo três para cada cliente que aceitou participar do estudo para cada um dos seis terapeutas inexperientes (i.e., até dois anos de prática) e para cada um dos seis terapeutas experientes (i.e., acima de dois anos de prática), perfazendo um total de 81 sessões. Houve orientações em $100 \%$ das sessões dos terapeutas inexperientes e $92,6 \%$ das sessões dos terapeutas experientes. Apesar da diferença estatisticamente significativa entre as duas porcentagens, é possível perceber a alta incidência de orientações por terapeutas experientes e inexperientes (acima de 90\%), como observado em Falcão (2011). Ao se comparar as porcentagens de sessões que houve auto-orientação, foi possível observar mais auto-orientações nas sessões de terapeutas experientes, porém, a diferença não foi estatisticamente significativa. As autoras defendem ser mais vantajoso, em termos terapêuticos, utilizar a estratégia de auto-orientação por parte dos clientes, pois assim estaria se aproveitando das vantagens do seguimento de regras (como a rapidez da mudança), prescindindo na necessidade do controle social ostensivo imposto pelo terapeuta ao emitir a orientação.

Quanto às porcentagens médias de orientações em função do número de falas, Donadone e Meyer (2005) encontram orientações em 9,6\% das falas entre os terapeutas pouco experientes e 1,5\% das falas dos terapeutas experientes. As únicas diferenças entre os tipos de orientações observadas entre terapeutas experientes e pouco experientes foi nas específicas, mais utilizadas por experientes, e nas para tarefas, utilizadas apenas por pouco experientes. De forma similar a Falcão (2011), portanto, Donadone e Meyer (2005) concluíram que a emissão de orientações/regras é uma forma de intervenção características de intervenções comportamentais, sejam analítica-comportamentais, sejam cognitivo-comportamentais.

Donadone e Meyer (2017), utilizaram os mesmos dados de Donadone e Meyer (2005) no intuito de analisar funcionalmente o comportamento dos terapeutas ao emitir orientações. As autoras identificaram que as tentativas frustradas de gerar auto-orientações por meio de solicitações de descrições de contingências foram os antecedentes mais frequentes às emissões de orientações pelos terapeutas, as quais foram seguidas da concordância dos clientes na maioria dos diálogos. Com base nessa nova análise de dados, as autoras concluíram que a emissão de orientações, apesar de amplamente utilizada, não é a primeira opção de terapeutas comportamentais.

O estudo teórico de Medeiros (2010), ao discutir extensamente os efeitos da emissão de regras por terapeutas, traz algumas reflexões acerca das razões pelas quais a emissão de regras (e.g., orientações) deve ser evitada e por talvez não ser a primeira opção de intervenção por terapeutas da TAC como constataram Donadone e Meyer (2017). De acordo com Medeiros (2010), a emissão de regras pode produzir efeitos deletérios à autonomia, à sensibilidade comportamental, à assertividade e 
à correspondência verbal do terapeutizando, assim, como ao vínculo terapêutico em si. De acordo com Medeiros e Medeiros (2012), ao proporem a Psicoterapia Comportamental Pragmática como um modelo de TAC menos diretivo, o desenvolvimento do repertório analítico do terapeutizando, além do autoconhecimento em si, é meta primordial da terapia de modo a minimizar a dependência do terapeutizando em relação ao terapeuta.

Como procedimento alternativo à emissão de regras, Medeiros e Medeiros (2012) propõem o procedimento denominado Questionamento Reflexivo. Esse procedimento tem como objetivo levar o cliente a emissão de dois tipos de regras: Regras analíticas, que consistem na descrição de contingências controladoras dos próprios comportamentos do terapeutizando (i.e., autorregras), assim como, dos comportamentos de outras pessoas de seu convívio; e autorregras modificadoras de comportamento, que consistem na descrição de modos como intervir sobre as variáveis de controle do comportamento do terapeutizando. O questionamento reflexivo, conforme ilustrado em Medeiros (2018), se dá por meio de questões abertas encadeadas nas falas do cliente. As cadeias de questões têm por meta fornecer estimulação suplementar (e.g., probes e prompts, Skinner, 1957), que favoreçam a emissão das regras pelo cliente, favorecendo o controle discriminativo das contingências sobre a suas respostas verbais (i.e., autorregras). Desse modo, o questionamento reflexivo vai além de solicitar que os terapeutizandos analisem o próprio comportamento, e sim, cria condições, por meio da estimulação suplementar, para que o terapeutizando tenha condições de fazê-lo.

Ainda, de acordo com Medeiros (2010), uma das justificativas para a preferência por levar o terapeutizando a emitir autorregras ao invés de meramente emiti-las é maior probabilidade de seguimento de autorregras modeladas que regras emitidas por outro falante. Por mais que essa asserção tenha sido demonstrada em pesquisa básica nos estudos clássicos de Catania e colaboradores (Catania, Matthews, \& Shimoff, 1982; Matthews, Catania, \& Shimoff, 1985; Shimoff, Matthew, \& Catania, 1986), ainda é necessária à sua verificação em estudos clínicos.
Souza et al. (2012) investigaram essa questão, realizando um estudo que tinha como objetivo verificar se os terapeutizandos relatavam terem seguido mais as regras emitidas por seus terapeutas ou as regras formuladas por eles mesmos, ou seja, autorregras. O estudo foi realizado em uma clínica escola de um centro universitário privado de Brasília. Participaram do estudo, três terapeutas estagiários e três terapeutizandos. Durante o estudo, foram gravadas em áudio digital três sessões de cada terapeutizando que foram posteriormente analisadas para a identificação e registro das regras emitidas pelos terapeutas e das regras emitidas pelos próprios clientes. Esta segunda categoria de regras foi dividida entre as autorregras elaboradas dentro das sessões terapêuticas por meio do questionamento reflexivo (i.e., autorregras geradas) e as autorregras elaboradas fora do contexto terapêutico (i.e., autorregras trazidas). Posteriormente, os áudios das cinco sessões seguintes foram analisados para verificar que tipo de regra foi seguida com maior frequência com base nos relatos verbais dos clientes.

Souza et al. (2012) observaram uma incidência de relatos de seguimento muito maior das autorregras geradas por meio do questionamento reflexivo em comparação às regras emitidas pelo terapeuta, sendo que as autorregras trazidas apresentaram níveis intermediários de seguimento. Todavia, apenas um dos três terapeutas do estudo emitiu regras e não gerou autorregras, enquanto que os outros dois terapeutas não emitiram regras, utilizando apenas o questionamento reflexivo. Sendo assim, um mesmo terapeuta não emitiu e gerou regras, o que impossibilitou uma comparação mais fidedigna dos dois procedimentos.

O presente trabalho consistiu numa replicação do estudo de Souza et al. (2012), porém, com a emissão de direta de regras e a geração de autorregras via questionamento reflexivo pelo mesmo terapeuta para duas terapeutizandas. O objetivo deste trabalho foi investigar que tipos de regras, como forma de intervenção terapêutica, são mais frequentemente seguidas pelos terapeutizandos em TAC com base em seus relatos em sessões subsequentes. 


\section{Método}

\section{Participantes}

A pesquisa foi realizada com duas terapeutizandas e um terapeuta estagiário de uma clínica escola de Brasília. As participantes da pesquisa foram escolhidas de forma aleatória entre os terapeutizandos atendidos pelo estagiário/terapeuta. A participação dos clientes foi feita de forma voluntária e a concordância em participar da pesquisa foi feita por meio da assinatura dos Termos de Consentimento Livre e Esclarecido - TCLE.

\section{Descrições dos Casos:}

Caso 1: Aline é uma mulher com 37 anos durante a realização da pesquisa. Aline é servidora pública e é graduada em Psicologia. A terapeutizanda é divorciada e tem duas filhas, uma de 15 e outra de sete anos de idade. Nasceu em Salvador e mora em Brasília há quatro anos com a filha mais nova e a mãe. Aline está separada há três anos e a sua filha mais velha mora com o pai. Apresentou como queixa principal dificuldades de relacionamento com o ex-marido, o que afeta, inclusive, a sua relação com as filhas. Os comportamentos alvo na terapia estão relacionados com estas dificuldades em se relacionar com o ex-marido e sua atual esposa, por exemplo: agressões verbais com ambos, escrever cartas e e-mails que não são lidos por ele, discussões sobre a forma de educação das filhas etc. Também foram elencados alguns comportamentos alvo em outros contextos da vida da cliente, tais como: dificuldade de exposição de suas ideias no ambiente de trabalho, sair para se divertir com os colegas de trabalho e fazer programas nos finais de semana acompanhada de outras pessoas. Por fim, a cliente também se queixou de dificuldades de se expor em sala de aula.

Tabela 1 - Regras emitidas e geradas nos contextos de vida das participantes do estudo.

\begin{tabular}{|c|c|c|c|}
\hline Terapeutizanda & Contextos de Vida & Regras Emitidas & Regras Geradas \\
\hline \multirow{3}{*}{ Aline } & $\begin{array}{l}1 \text { - Telefonemas ex- } \\
\text { marido }\end{array}$ & $\begin{array}{l}\text { "Desligue o telefone quando o } \\
\text { seu ex começar a te xingar" }\end{array}$ & $\begin{array}{l}\text { "Preciso defender o meu ponto de } \\
\text { vista" }\end{array}$ \\
\hline & 2 - Vida social & $\begin{array}{l}\text { "Saia com os colegas de } \\
\text { trabalho" }\end{array}$ & $\begin{array}{l}\text { "Devo sair com outras pessoas nos } \\
\text { finais de semana" }\end{array}$ \\
\hline & 3 - Exposição em público & $\begin{array}{l}\text { "Treine a leitura em frente ao } \\
\text { espelho" }\end{array}$ & $\begin{array}{l}\text { "Vou me oferecer a ler em voz alta } \\
\text { na sala de aula" }\end{array}$ \\
\hline \multirow{3}{*}{ Cláudia } & 1 - Pensão alimentícia & $\begin{array}{l}\text { "Consulte a defensoria pública } \\
\text { da união" }\end{array}$ & $\begin{array}{l}\text { "Tenho que conversar com o pai da } \\
\text { criança sobre a pensão" }\end{array}$ \\
\hline & 2 - Procura de emprego & $\begin{array}{l}\text { "Você pode fazer um cadastro } \\
\text { em agências de emprego" }\end{array}$ & $\begin{array}{l}\text { "Preciso entregar o meu currículo } \\
\text { nas empresas" }\end{array}$ \\
\hline & $\begin{array}{l}3 \text { - Qualificação } \\
\text { Profissional }\end{array}$ & $\begin{array}{l}\text { "Você pode procurar cursos } \\
\text { gratuitos e de baixo custo" }\end{array}$ & $\begin{array}{l}\text { "Vou procurar cursos de idiomas na } \\
\text { internet" }\end{array}$ \\
\hline
\end{tabular}

Nota: Na Tabela 1, são descritos os contextos específicos de vida relativos às queixas e aos comportamentos alvo das participantes; as regras emitidas pelo terapeuta e as autorregras geradas durante as sessões preliminares do processo terapêutico.

Caso 2: Cláudia, durante a realização da pesquisa, tinha 23 anos, estava solteira e tinha um filho de dois anos de idade. Nasceu e mora em Brasília com sua mãe, o filho e uma irmã. Cláudia tinha o segundo grau completo e estava desempregada no período que estava em tratamento. A queixa prin- cipal ao procurar terapia está relacionada ao fato de ter sofrido agressões físicas por parte do ex-namorado, pai do seu filho, eventos que a levaram a procurar ajuda policial, desencadeando em um processo da Lei Maria da Penha. A cliente foi encaminhada à clínica escola pela Juíza que acom- 
panha o caso. Os comportamentos definidos como alvo estão diretamente ligados à sua relação com o pai do seu filho, por exemplo: reagir ao receber ameaças físicas, permanecer ouvindo xingamentos por telefone, conversar sobre a pensão alimentícia para o filho, encontrar com o ex-namorado de forma desprotegida, iniciar relacionamentos afetivos onde ela é desrespeitada. Em outros contextos da vida da cliente, voltados para sua qualificação profissional e procura de emprego, também foram definidos comportamentos alvo, tais como: preparar Curriculum vitae, fazer cadastro em agências de emprego, procurar cursos profissionalizantes, fazer uma rede de relacionamentos profissionais etc. (Tabela 1).

\section{Local:}

As sessões ocorreram nos consultórios de uma clínica escola de um centro universitário em Brasília. Os consultórios mediam $4 \mathrm{x} 3 \mathrm{~m}^{2}$ e continham uma mesa, duas cadeiras de escritório, duas poltronas viradas uma de frente para outra, onde sentavam-se terapeuta e terapeutizanda, relógio para controle da duração da sessão, ar-condicionado, iluminação artificial, espelho unidirecional e sistema de captação de áudio para observação das sessões.

\section{Materiais/Equipamentos/Instrumentos}

Foi utilizado um gravador de voz digital MP3 para registro acústicos das interações entre o terapeuta e as terapeutizandas. Um protocolo de registros foi utilizado para a registro das respostas verbais do terapeuta e das terapeutizandas com base nos arquivos de áudio.

\section{Procedimento}

As sessões foram gravadas em áudio digital, oito para a terapeutizanda Aline e sete para a terapeutizanda Cláudia e posteriormente transcritas. A partir da terceira sessão, tempo dedicado para o levantamento de dados, estabelecimento do vínculo terapêutico e a realização das análises funcionais individuais, foi iniciado o procedimento do estudo propriamente dito. Sendo assim, as gravações foram iniciadas a partir da quarta sessão para cada uma das terapeutizandas. $\mathrm{Na} 4^{\mathrm{a}}$, $5^{\mathrm{a}}$ e $6^{\mathrm{a}}$ sessão para Aline e $4^{\mathrm{a}}$ e $5^{\mathrm{a}}$ para Cláudia, foram emitidas três regras em três contextos específicos da vida das te- rapeutizandas e aplicado o procedimento do questionamento reflexivo, no intuito de levá-las a formular outras três autorregras relativas aos mesmos contextos específicos de suas vidas. Com base nas transcrições dessas sessões, verificou-se a emissão das regras pelo terapeuta, a aplicação do questionamento reflexivo e a emissão das autorregras pelas terapeutizandas.

As regras foram divididas em duas categorias: Regras emitidas pelo terapeuta durante as sessões de psicoterapia e autorregras formuladas pelas terapeutizandas também durante o processo terapêutico, denominadas Autorregras Geradas. As regras emitidas ou geradas foram definidas como descrições de contingências que podem controlar os comportamentos das terapeutizandas e das pessoas do seu convívio (regras analíticas) e a descrição de modos de atuação visando a mudança dessas contingências (regras modificadoras de comportamentos). As autorregras geradas foram evocadas por meio de questionamento reflexivo, definido como um procedimento terapêutico composto por conjuntos de questões abertas encadeadas de forma lógica, formuladas pelo terapeuta, com o objetivo de favorecer o controle discriminativos das contingências sobre o comportamento verbal do terapeutizando (i.e., emissão de autorregras analíticas), assim como, levá-lo a formular modos de operar sobre tais contingências (i.e., emissão de autorregras modificadoras de comportamentos).

Foram transcritos dois trechos de diálogos ocorridos durante as sessões de terapia para cada participante da pesquisa no intuito de ilustrar a emissão de regras pelo terapeuta e a aplicação do questionamento reflexivo. Para cada transcrição, o primeiro trecho apresenta a emissão de uma regra por parte do terapeuta e, no segundo, é demonstrado o questionamento reflexivo com a consequente emissão de uma autorregra pela terapeutizanda.

\section{Diálogo 1 (Aline) - Emissão da Regra pelo Terapeuta}

T (Terapeuta): Aline, você tem falado ultimamente com o seu ex-marido?

Aline: Bem pouco, a maioria das vezes por telefone para tratar sobre questões relacionadas às nossas filhas, mas é sempre aquele stress, quando eu começo a falar ele me corta e já dispara o falatório. 
T: Como assim?

Aline: Ele não me escuta de jeito nenhum, eu fico do outro lado da linha morta de raiva, só escutando a gritaria dele.

T: Se é assim, porque você fica escutando e não desliga o telefone? (Emissão da regra pelo terapeuta).

Aline: Acho que é isso mesmo que eu vou fazer, ele não está interessado no que eu tenho a dizer mesmo!

\section{Diálogo 2 (Aline) - Questionamento Reflexivo}

Aline: O João (nome fictício), pai das meninas me ligou para tratar sobre as férias de julho.

T: Como foi a conversa de vocês?

Aline: Bem.... No início ele já veio definindo que as meninas iam viajar com ele e a esposa no início do mês.

T: Como fica essa data para você e as suas filhas?

Aline: Não sei, porque eu também estava programando um passeio para a mesma época.

T: No início do mês?

Aline: Isso. Inclusive já marquei até férias para o período. Então eu teria que mudar as férias o que é um problema no meu trabalho.

T: Como se dá a marcação de férias de seu ex-marido?

Aline: Ele é autônomo e não tem este problema.

T: Você disse que nas férias de final de ano aconteceu a mesma coisa e você ficou calada mesmo ficando prejudicada.

Aline: Foi mesmo, acabei tendo que ficar menos tempo na praia com as meninas.

T: Você acha que dava para ter sido diferente? De uma forma que ficasse melhor pra todos?

Aline: Acho que sim, porque quem levou a pior fui eu!

T: Que caminhos você poderia ter tentado para as férias terem sido diferentes?

Aline: Eu não deveria ter aceitado a situação como definitiva e mostrado como ficaria melhor para mim. T: O que impediu você fazer isto?

Aline: O desgaste de uma conversa com o João, é sempre muito difícil dele aceitar qualquer contraproposta.

T: E sem enfrentar este desgaste, como a situação poderia ter se resolvido?

Aline: Não tinha outra maneira, só conversando e negociando, para que eu não fique sempre submetida à vontade dele.
T: E aí, de que forma você acha que deve agir com relação ao problema das férias de julho?

Aline: É eu acho que tenho que conversar e explicar como eu tinha me programado, falar da dificuldade de mudar o meu período de férias..., bem, defender o meu ponto de vista. Não vejo outro jeito! (Emissão de autorregras pela terapeutizanda)

T: Concordo com você, boa sorte!

\section{Diálogo 1 (Cláudia) - Emissão de Regra pelo Terapeuta}

Cláudia: Neste final de semana o pai do meu filho esteve lá em casa para irmos juntos fazer compras de material escolar que ele está precisando.

$\mathbf{T}$ (Terapeuta): Cláudia, ele paga pensão alimentícia para o seu filho?

Cláudia: Não, ás vezes quando eu peço, ele ajuda com alguma coisa.

T: Acho que você deveria procurar a Defensoria Pública com o objetivo de estabelecer o pagamento de pensão alimentícia para seu filho, só assim ele teria que comparecer com o valor definido pela justiça. (Emissão de Regra pelo Terapeuta)

Cláudia: Sem dúvidas, acho que ele deveria ser obrigado a pagar a pensão a ser descontada direto do seu salário.

T: É isso mesmo, penso que você deveria ir até a Defensoria para se informar melhor sobre este assunto. (Emissão de Regra pelo Terapeuta)

Cláudia: Vou fazer isto o mais rápido possível, depois eu te falo como ficou resolvido.

\section{Diálogo 2 (Cláudia) - Questionamento Reflexivo}

Cláudia: O pai do meu filho foi lá em casa ontem à noite e nós fomos juntos ao mercado para comprar umas coisas que estavam faltando, somente coisas para o menino, como: iogurte, biscoitos, leite, suco etc.

T: Cláudia, como que ele ficou sabendo que estas coisas estavam faltando?

Cláudia: Eu telefonei para ele. Todo mês eu tenho que ligar para lembrá-lo destas coisas. Às vezes ele já chega com tudo comprado e nem sempre é o que estava precisando mais.

T: De que outra forma você acha que esta situação poderia ser resolvida?

Cláudia: Não sei exatamente. Mas uma coisa eu sei. 
Como sou eu que convivo no dia-a-dia com meu filho, então eu sei o que ele realmente está necessitando.

T: Bom, então vamos pensar juntos, se o seu filho mora com você, certamente você melhor que ninguém sabe do que ele precisa, mas por outro lado, é o pai do seu filho que muitas vezes tem comprado estas coisas para ele, então vocês dois tem função importante nesta questão, o que você acha disso? Cláudia: Eu sei que o papel dele é importante, principalmente porque estou desempregada, senão eu mesma comprava. O problema é que muitas vezes ele não se lembra de depositar ou trazer o dinheiro, ou então, compra o que não está precisando.

Cláudia: Estou entendendo que se você tivesse o dinheiro, em sua opinião, você seria mais capaz de comprar o que seu filho está realmente precisando. Cláudia: É isso mesmo, só que o dinheiro não poderia faltar, porque as coisas acabam e tem que comprar tudo de novo.

T: Considerando que você não tem uma renda fixa atualmente, como você poderia resolver isto?

Cláudia: Eu teria que pedir o dinheiro para o meu ex-namorado, mas ele tinha que ter o compromisso de não faltar com este dinheiro. Só que ele não é organizado com dinheiro, quando nós estávamos juntos, eu que cuidava do dinheiro dele.

T: Pense em uma forma para que você pudesse garantir que este dinheiro estivesse disponível todos os meses?

Cláudia: Não vejo outra maneira, vou ter que falar com ele sobre pagamento da pensão alimentícia, penso que só assim a coisa poderia ser resolvida. (Emissão de autorregras pela terapeutizanda)

As transcrições dos áudios das sessões subsequentes para as duas terapeutizandas (Sessões de 7 à 11 para Aline; 6 à 10 para Cláudia) foram analisadas, contabilizando-se os relatos de seguimento das regras em função das oportunidades de seguimento, ou seja, a partir dos relatos de exposição às contingências descritas pelas regras. Foi feita a comparação da quantidade de relatos de seguimento em função das oportunidades de seguimento dos dois tipos de regra, as autorregras geradas via questionamento reflexivo e as regras emitidas pelo terapeuta.

Durante as análises das sessões foram consideradas como seguimento ou oportunidades de seguimento das regras, situações corriqueiras vi- venciadas pelas terapeutizandas que pudessem ser identificadas como pertencentes a um dos contextos de vida nos quais as regras foram emitidas ou geradas. Por exemplo, se a terapeutizanda Aline recebeu um convite para sair para um happy hour com os colegas de trabalho, este fato nas análises dos relatos das sessões, foi contabilizado como uma oportunidade de seguimento de regras dentro do contexto melhoria da vida social. Se o convite foi aceito, o fato também foi contabilizado como seguimento da regra emitida "Sair com os colegas de trabalho", dentro do mesmo contexto da vida da terapeutizanda.

\section{Fidedignidade}

Um observador independente ignorante quanto aos objetivos da pesquisa foi treinado no registro de frequência das categorias do estudo (regras emitidas; autorregras geradas; relatos de oportunidades de seguimento e relatos de seguimento de regras e autorregras). Este observador analisou três sessões transcritas de Aline e duas de Cláudia. Foram comparados os registros do experimentador e do observador independente quanto a essas cinco sessões transcritas. O índice de fidedignidade foi calculado dividindo-se as concordâncias multiplicadas por 100 pelas discordâncias adicionadas às concordâncias. Os índices variaram entre $72,5 \%$ e $98 \%$ para Cláudia e 70\% e 91,25\% para Aline.

\section{Resultados}

As análises das sessões 4, 5 e 6 de Aline e 4 e 5 de Cláudia revelaram que as autorregras geradas foram emitidas após o questionamento reflexivo. Nessas sessões também foi possível constatar as regras emitidas pelo terapeuta.

A Figura 1 mostra as frequências de relatos de seguimento das regras geradas e autorregras emitidas nos contextos de vida específicos de Aline, além da frequência de oportunidades de seguimento das mesmas regras. Com base na Figura 1, ainda é possível visualizar as porcentagens de seguimento em função da frequência de oportunidades.

Por meio da Figura 1, é possível verificar que houve mais oportunidade de seguimento de regras quanto ao contexto Vida Social. Houve mais oportunidade de seguimento das autorregras geradas que das regras emitidas nos três contextos, sendo 


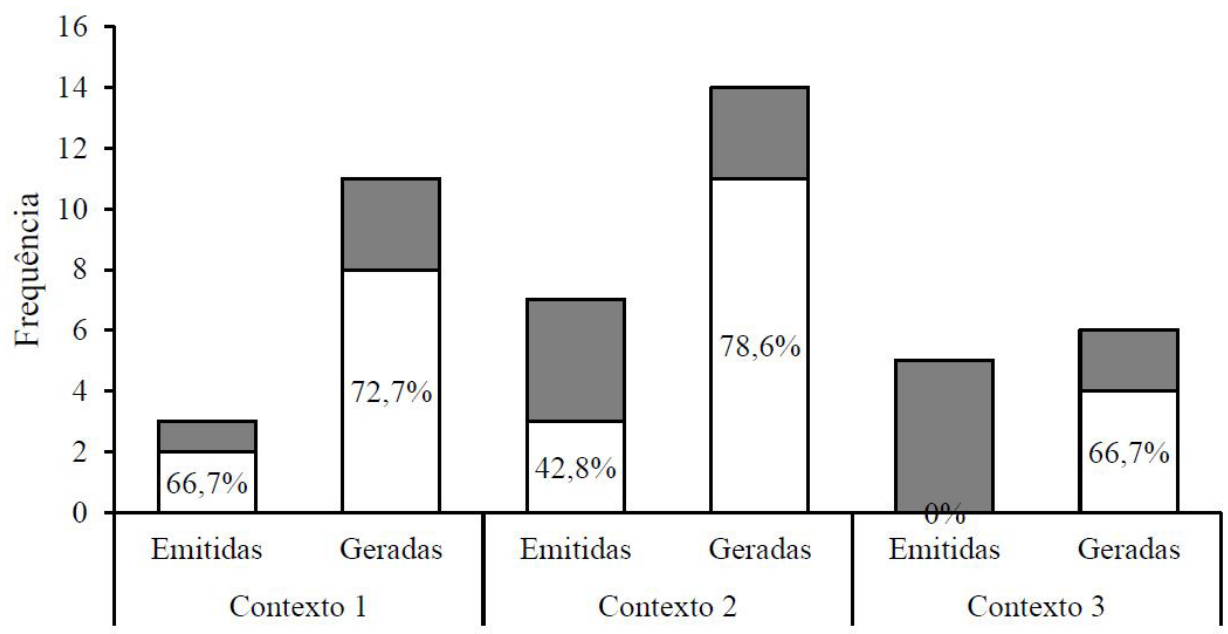

Contextos de Vida

Figura 1. Frequência de relatos de seguimento de regras emitidas, de autorregras geradas e de oportunidades de seguimento para Aline em função dos contextos de vida. As colunas representam o total de oportunidades de seguimento, sendo as suas partes claras relativas à frequência de relatos de seguimento, as quais contêm numericamente as porcentagens.

que a menor diferença quanto às oportunidades de emissão ocorreu no Contexto 3 - Exposição em Público. Com base na Figura 1, as autorregras geradas foram seguidas com uma frequência maior que as regras emitidas, apresentando assim, maiores porcentagens de relatos de seguimento. Vale destacar que a regra emitida no contexto Exposição em Público não foi seguida em nenhuma das cinco oportunidades.

A Figura 2 contém as frequências de seguimento das autorregras geradas e emitidas nos três contextos de vida para participante Cláudia, assim como as porcentagens de relatos de seguimento em função das oportunidades.

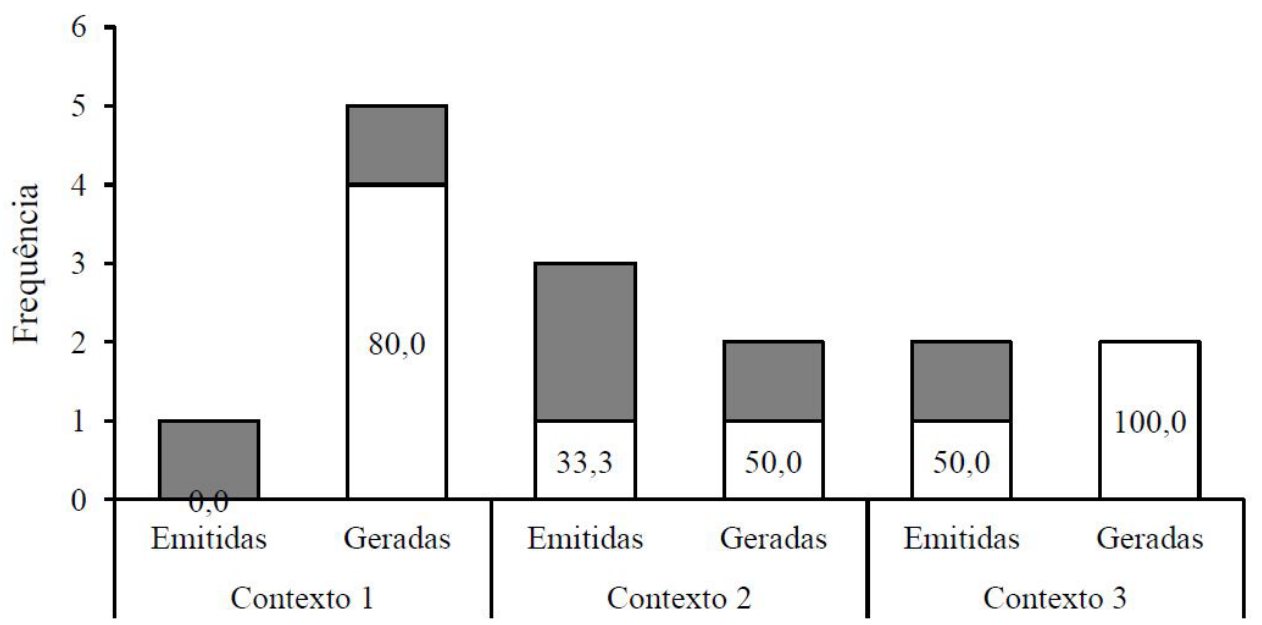

Contextos de Vida

Figura 2. Frequência de relatos de seguimento de regras emitidas, de autorregras geradas e de oportunidades de seguimento para Cláudia em função dos contextos de vida. As colunas representam o total de oportunidades de seguimento, sendo as suas partes claras relativas à frequência de relatos de seguimento, as quais contêm numericamente as porcentagens. 
Os relatos de oportunidades de seguimento nos três contextos de vida de Cláudia foram variaram entre quatro e seis (Figura 2). As frequências de oportunidades de seguimento nos três contextos de vida foram similares entre regras emitidas e autorregras geradas, com exceção do contexto Pensão Alimentícia, no qual, cinco das seis oportunidades de seguimento foram para a autorregra gerada. De modo similar ao observado com Aline, Cláudia apresentou maiores porcentagens de relatos de seguimento das autorregras geradas em relação às emitidas, sendo que a regra emitida no contexto Pensão Alimentícia não foi seguida e a autorregra gerada no Contexto 3 - Qualificação Profissional foi seguida em todas as oportunidades com base no relato da terapeutizanda.

\section{Discussão}

$\mathrm{Na}$ presente pesquisa, foi comparado o número de relatos de seguimento em função das oportunidades de seguimento de regras emitidas pelo terapeuta com as autorregras geradas no processo terapêutico via questionamento reflexivo. Os resultados apresentados nesta pesquisa permitem que sejam feitas considerações importantes sobre a utilização de regras e autorregras na TAC. A despeito de todas as limitações metodológicas como as observadas na presente pesquisa, ficou evidente, com base nos resultados das duas terapeutizandas, que as autorregras geradas foram seguidas com frequências e porcentagens superiores às emitidas pelo terapeuta. Em outras palavras, pode ser observado, nas Figuras 1 e 2, que os relatos de seguimento de regras emitidas, considerando as oportunidades de seguimento foram baixos em comparação com as autorregras geradas nas mesmas situações.

O baixo número de relatos de seguimento de regras emitidas pelo terapeuta na presente pesquisa também foi reportado no estudo Souza et al. (2012), ainda que a emissão de regras por parte do terapeuta tenha sido mínima em seu estudo. Em Souza e cols. a emissão de regras e a geração de autorregras não foi manipulada diretamente, e sim, apenas medida pelas observações dos registros de áudio das sessões. Já no presente trabalho, foi realizada a manipulação direta da emissão de regras pelo terapeuta e geração de autorregras emitidas pela terapeutizanda por meio do questionamento reflexivo (Medeiros, 2018; Medeiros \& Medeiros, 2012). Assim, foi possível comparar as frequências de relatos de seguimento dos dois tipos de regras, apontando para a maior eficácia da geração de novas regras por meio do questionamento reflexivo.

O questionamento reflexivo, procedimento descrito por Medeiros e Medeiros (2012) e Medeiros (2018), se mostrou, mais uma vez, um instrumento eficaz no estabelecimento de autorregras. O mesmo foi demonstrado nos estudos de R. M. Medeiros (2016) e Lettieri (2017), em pesquisa básica. Em R. M. Medeiros (2016), o questionamento reflexivo foi eficaz em gerar autorregras descritivas do reforçamento diferencial aplicado às respostas verbais dos participantes acerca de temas de menor e maior interesse. Todavia, como o reforçamento diferencial em Moraes já havia modificado a frequência das respostas verbais acerca temas específicos, não foi possível avaliar o efeito do questionamento reflexivo e das autorregras geradas sobre os temas dos episódios verbais nas fases subsequentes do estudo.

Já em Lettieri (2017), o questionamento reflexivo foi eficaz em levar os participantes a identificar a maior probabilidade de reforçamento para relatos distorcidos em um jogo de cartas. Para os seis dos nove participantes que emitiram a autorregra após o questionamento reflexivo, foi possível verificar um aumento na frequência de relatos distorcidos após o questionamento reflexivo. O presente estudo, não avaliou, todavia, a eficácia do questionamento reflexivo em gerar autorregras e sim, se aquelas geradas por esse procedimento tiveram mais relatos de seguimento que as emitidas pelo terapeuta. Novas pesquisas poderiam ser conduzidas para avaliar a eficácia do questionamento reflexivo na emissão de autorregras no contexto aplicado. A despeito disso, com base nas análises das sessões 4, 5 e 6 de Aline e 4 e 5 de Cláudia, foi possível observar que elas emitiram as autorregras geradas mediante o questionamento reflexivo.

A regra "desligue o telefone quando o seu marido começar a xingá-la" foi aquela seguida com maior frequência $(66,7 \%)$ dentre as emitidas pelo terapeuta. Uma possibilidade de explicação incidência de seguimento dessa regra em porcentagem similar a das autorregras geradas pode ter sido o fato de que Aline já havia emitido essa regra espontaneamente antes da sua emissão pelo terapeuta. Nesse caso, é 
possível supor que, na realidade, já se tratava de uma autorregra, porém, não gerada devido à aplicação do questionamento reflexivo. Esse tido de autorregra foi frequente no estudo de Souza et al. (2012), sendo denominado de "autorregra trazida" ou seja, aquelas que as terapeutizandas já emitiam antes da terapia. Em Souza et al. (2012), as regras trazidas foram seguidas com uma frequência intermediária entre as emitidas pelos terapeutas e as geradas via questionamento reflexivo. De qualquer forma, a escolha dessa regra para a emissão pelo terapeuta se constituiu em um erro de aplicação do procedimento, que pode ser justificado pelo caráter dinâmico do processo terapêutico que dificulta a manipulação das variáveis com a precisão de pesquisas básicas.

Segundo Medeiros (2010), não há garantias do seguimento de regras emitidas nas formas de conselhos, ordens, orientações, sugestões ou instruções em situações cotidianas. Ainda que Albuquerque et al. (2012) tenham demonstrado que regras emitidas em formato de ordem tem uma probabilidade maior de serem seguidas do quem em formato de sugestões em pesquisa básica. Para o Medeiros (2010), o seguimento de regras em situações cotidianas usualmente ocorre quando a regra coincide com aquilo que ouvinte já faria em função de outras variáveis. O relato do ouvinte de que concorda com o conselho e de que o seguirá é pouco preciso, como discutem Medeiros e Medeiros (2018). Para os autores, dizer que concorda com a regra e que irá segui-la está sob o controle das consequências providas pelo ouvinte, no caso, o terapeuta. Porém, o comportamento descrito na regra está sob o controle de variáveis externas ao processo terapêutico que acontecem no dia-a-dia dos terapeutizandos. Como afirmam Chamati e Pergher (2009), Pergher (2002), LIoyd (2002), Beckert (2005), Medeiros (2002a; 2002b), Medeiros e Medeiros (2018), a diferença nas variáveis de controle entre o dizer (relatar que seguirá a regra) e o fazer (agir de acordo com a regra) é responsável pela ausência de correspondência entre os dois comportamentos.

O seguimento de regras emitidas pela própria pessoa, de acordo com Medeiros (2010) e como o observado no presente estudo, é mais provável de ocorrer que o seguimento de regras emitidas por outras pessoas. Isso ocorre por algumas razões:
1. Em pesquisa básica, a maior probabilidade de seguimento de autorregras modeladas em relação às emitidas pelo experimentador foi demonstrada num conjunto de estudos clássicos conduzidos por Catania e colaboradores (Catania et al., 1982; Matthews et al.., 1985; Shimoff et al., 1986).

2. A emissão de autorregras, de acordo com Skinner (1974), já pressupõe, em alguma medida, o controle pela contingência, ainda que esta possa controlar apenas a descrição verbal da contingência e não o se comportar de acordo com ela. Quando outra pessoa emite a regra, no caso, um terapeuta, a contingência ainda não controla, de forma acurada, a emissão de sua descrição por parte do ouvinte. Não há garantias de que a descrição da contingência emitida por outra pessoa favoreça que o ouvinte passe a emitir tatos (i.e., respostas verbais sob o controle discriminativo de estímulos não verbais; Perterson, 1978) sob o controle discriminativo da contingência em si. As repetições das regras pelo ouvinte podem se constituir em intraverbais (i.e., resposta verbais sobre controle discriminativo de estímulos não verbais sem correspondência ponto-a-ponto entre o estímulo e a resposta verbais, Peterson, 1978) e não em tatos, o que indica o controle verbal da regra sobre o comportamento verbal do ouvinte e não o controle da contingência sobre a sua resposta verbal. Ou seja, a emissão de regras por um terapeuta pode não favorecer o controle pela contingência descrita na regra sobre o comportamento verbal do ouvinte e nem sobre o comportamento descrito na regra. Isso explicaria a ausência de correspondência dizer-fazer diante da emissão de regras por outras pessoas, como reportado nos estudos de Catania e colaboradores na década de 80. Quando Cláudia diz que deveria exigir que o ex-namorado pague pensão alimentícia para poder administrar melhor o dinheiro para atender as necessidades do filho após o terapeuta emitir a regra de que ela deve fazê-lo, é mais provável que a sua resposta verbal seja um intraverbal e não um tato. Ou seja, a sua resposta verbal estaria mais sob o controle do estímulo verbal apresentado pelo terapeuta (i.e., regra) do que sob o controle da contingência como estímulo discriminativo não verbal. 
3. A emissão de regras pode resultar no que Baum (2005/2006) denomina diminuição da sensação de liberdade. A emissão de regras demonstra de modo ostensivo a tentativa de controle por um agente controlador, no caso o terapeuta (Skinner, 1953). Por mais que muitos terapeutizandos demandem conselhos e orientações de seus terapeutas, a sua apresentação pode ter funções aversivas para outros, principalmente quando contrariam aquilo que tenderiam a fazer (Medeiros, 2010). Os conselhos do terapeuta, por mais que sejam embasados em análises funcionais, raramente diferem daquilo que outras pessoas do convívio do terapeutizando já disseram. Fora o efeito da figura de autoridade do terapeuta (Skinner, 1974), não há razões para supor que terapeutizando seguiria as regras emitidas pelo terapeuta, uma vez que já não está seguindo as mesmas regras emitidas por amigos e familiares.

4. O seguimento de regras pode envolver duas contingências, como descreve Baum (2005/2006). Uma é a contingência próxima, isto é, a que diz respeito aos efeitos do seguimento ou não da regra sobre o falante que proverá consequências diferenciais que afetarão o seguimento da regra por parte do ouvinte. A outra é a contingência última, ou seja, a descrita na regra. Zettle e Hayes (1982) denominam o controle pela contingência próxima de aquiescência e o controle pela contingência última de rastreamento. Para Skinner (1974), as consequências apresentadas pelo falante ao seguimento da regra são fundamentais para o controle por regras. Por outro lado, para que a contingência próxima vigore, é fundamental que o falante tenha acesso ao seguimento ou não da regra, o que raramente ocorre no contexto terapêutico. Com exceção dos comportamentos alvo que ocorrem na sessão (Kohlenberg \& Tsai, 1991), quando o terapeutizando se depara com a contingência descrita na regra, o terapeuta não está presente. Ou seja, o controle pela contingência próxima é enfraquecido. Todavia, quando se tratam de autorregras, o falante e o ouvinte são a mesma pessoa, de modo que o controle pela contingência próxima pode se manter, prescindindo do controle social externo, como sugerem Donadone e Meyer (2005).

Mesmo as regras geradas no presente trabalho não foram seguidas em todas as oportunidades de seguimento. Segundo Medeiros (2010), a mudança no comportamento verbal dos clientes nem sempre é acompanhada pela mudança do comportamento não verbal correspondente. Para Beckert (2005), comportamentos verbais e comportamentos não verbais são operantes distintos, mantidos por contingências diversas. De acordo com Medeiros e Medeiros (2018), dizer que agirá de determinada maneira pode estar sob o controle das consequências apresentada pelo terapeuta e o agir, em si, está sob o controle de variáveis fora da terapia. De acordo com os autores, os terapeutas devem ter muito cuidado ao evocar e consequenciar a emissão de autorregras de modo a não comprometer a correspondência verbal. $\mathrm{O}$ uso de perguntas fechadas, a liberação de reforçadores arbitrários contingentes ao dizer e a emissão de regras são apontados por Medeiros e Medeiros (2018) como práticas do terapeuta mais correlacionadas com a ausência de correspondência verbal. O presente trabalho corroborou a baixa correspondência dizer-fazer quanto as regras eram emitidas pelo terapeuta.

O seguimento ou não das regras no presente estudo foi aferido com base no relato verbal das terapeutizandas nas sessões subsequentes à emissão ou à geração de regras. Essa é uma limitação metodológica relevante, uma vez que o pesquisador não tem instrumentos para a verificação da correspondência verbal dos relatos de seguimento de regras ou autorregras. Como discutem Medeiros e Medeiros (2018) e demonstram Medeiros, Oliveira, e Silva (2013), a ausência de checagem está correlacionada com a ausência de correspondência verbal. Sendo assim, não é possível afirmar que as regras foram seguidas ou não, e sim, que tipo de regra teve mais relatos de seguimento em função das oportunidades de seguimento também relatadas. Uma alternativa para minimizar essa limitação seria utilizar apenas comportamentos alvo emitidos (Kohenberg \& Tsai, 1991; Medeiros \& Medeiros, 2012), isto é, aqueles que ocorrem na sessão, sendo passíveis de observação direta por parte do terapeuta.

Houve mais relatos de oportunidades de seguimento das regras geradas em relação às emitidas. A despeito da possibilidade de esse resultado se dever a casualidade das ocorrências de oportunidades no dia-a-dia das terapeutizandas, pode-se hipotetizar que estas se expuseram mais às situações nas quais 
teriam a oportunidade de se comportar de acordo com as autorregras em relação às regras emitidas pelo terapeuta. Outra possibilidade seria a de o terapeuta inadvertidamente ter feito mais perguntas sobre oportunidades de seguimentos de regras geradas, o que enviesaria essa medida. Mais replicações seriam necessárias para aferir a possibilidade de que não só os terapeutizandos tendem a seguir as autorregras, como também, se expõem mais às situações onde teriam oportunidade de segui-las.

Por mais que se tenha tido o cuidado em se equiparar a dificuldade de seguimento de regras emitidas e geradas, ainda é possível questionar se os resultados obtidos não se constituiriam em artefato do método. Caso as regras emitidas fossem de mais difícil seguimento que as autorregras geradas, a superioridade de relatos de seguimento das geradas não serviria de evidência da maior eficácia das autorregras em relação às regras. Novamente, seriam necessárias mais replicações com outros participantes, em outros contextos de vida e outras regras, para aferir essa possibilidade.

A despeito das limitações metodológicas, o presente trabalho traz importantes contribuições acerca do efeito de práticas comuns de terapeutas analítico-comportamentais. Além disso, contém uma inovação metodológica em pesquisas de processo, oferendo uma alternativa aos estudos de caso único (Cozby, 2001/2003) e de ensaios clínicos randomizados (Leonardi, 2017). Por fim, essa pesquisa contribuiu para a reflexão o uso de regras na clínica como forma de estabelecer autoconhecimento e propiciar a mudança de comportamentos alvo.

\section{Referências}

Abreu-Rodrigues, J. \& Sanábio-Heck, T. E. (2004). Instruções e auto-instruções: Contribuições da pesquisa básica. Em C. N. Abreu \& H. J. Guilhardi (Orgs.), Terapia comportamental e Cognitivocomportamental: Práticas clínicas (pp. 152-168). São Paulo: Editora Rocca.

Albuquerque, L. C., \& Ferreira, K. V. D. (2001). Efeitos de regras com diferentes extensões sobre o comportamento humano. Psicologia: reflexão e crítica, 14(1), 143-155.

Albuquerque, L. C., \& Paracampo, C. C. P. (2010). Análise do controle por regras. Psicologia
USP, 21(2), 253-273.

Albuquerque, L. C., \& Silva, F. M. (2006). Efeitos da exposição a mudanças nas contingências sobre o seguir regras. Psicologia: Teoria e Pesquisa, 22, 101-112.

Albuquerque, L. C., de Souza, D. G., Matos, M. A., \& Paracampo, C. C. P. (2003). Análise dos efeitos de histórias experimentais sobre o seguimento subsequente de regras. Acta Comportamentalia, 11, $87-126$.

Albuquerque, L. C., Matos, M. A., de Souza, D. D. G., \& Paracampo, C. C. P. (2004). Investigação do controle por regras e do controle por histórias de reforço sobre o comportamento humano. Psicologia: Reflexão e Crítica, 17(3), 395-412. doi: 10.1590/S0102-79722004000300012

Albuquerque, L. C., Mescouto, W. A., \& Paracampo, C. C. P. (2011). Controle por regras: efeitos de perguntas, sugestões e ordens. Acta Comportamentalia, 19, 19-42.

Albuquerque, L. C., Paracampo, C. C. P., Matsuo, G. L., \& Mescouto, W. A. (2013). Variáveis combinadas, comportamento governado por regras e comportamento modelado por contingências. Acta Comportamentalia, 21, 285-304.

Albuquerque, L. C., Silva, L. S., \& Paracampo, C. C. P. (2014). Análise de variáveis que podem interferir no comportamento de seguir regras discrepantes. Acta Comportamentalia, 22, 51-71.

Barrett, D. H., Deitz, S. M., Gaydos, G. R., \& Quinn, P. C. (1987). The effects of programmed contingencies and social conditions on response stereotypy with human subjects. The Psychological Record, 37(4), 489-505. doi: 10.1007/BF03394995

Baum, W. M. (2005/2006). Compreender o behaviorismo: Comportamento, cultura e evolução. M. T. A. Silva \& M. T. A. Silva., M. A. Matos. \& G. Y. Tomanary (Trads.). Porto Alegre: Artmed.

Beckert, M. E. (2005). Correspondência verbal/ não-verbal: pesquisa básica e aplicações na clínica. Em J. Abreu-Rodrigues, \& M. R. Ribeiro (Orgs.), Análise do comportamento: Pesquisa, teoria e aplicação (pp. 229 - 244). Porto Alegre: Artes Médicas.

Blakely, E., \& Schlinger, H. D. (1987). Rules: Function-altering contingency specifying stimuli. The Behavior Analyst, 10, 183-187. 
Catania, A. C., Matthews, B. A., \& Shimoff, E. (1982). Instructed versus shaped human verbal behavior: Interactions with nonverbal responding. Journal of the Experimental Analysis of Behavior, 38, 233-248. doi:10.1901/ jeab.1982.38-233.

Cerutti, T. D. (1989). Discrimination theory of rulegoverned behavior. Journal of the Experimental Analysis of Behavior, 51 (2), 259-276.

Chamati, A. B. D. T., \& Pergher, N. K. (2009). Modelagem do comportamento de falar a verdade em sessões de terapia. Revista Psicolog, 02, 65-76.

Cozby, P. C. (2001/2003). Métodos de pesquisa em ciências do comportamento. P. I. C. Gomide, \& E. Otta (Trads.) São Paulo: Atlas.

Donadone, J. C., \& Meyer, S. (2005). Orientação e auto-orientação em atendimentos de terapeutas analítico-comportamentais experientes e pouco experientes. Revista Brasileira de Terapia Comportamental e Cognitiva, 7(2), 219-229. doi: $10.31505 /$ rbtcc.v7i2.31

Donadone, J. C., \& Meyer, S. (2017). Análise de contingências de orientações em intervenções clínicas comportamentais. Fragmentos de cultura, 27(2), 290-302. doi: 10.18224/frag.v27. n2.2017

Falcão, J. C. (2011). O que faz o terapeuta analítico- comportamental no consultório? (Monografia de Conclusão do curso de Graduação). UniCEUB, Brasília.

Ferster, C. B. (1972). An experimental analysis of clinical phenomena. The Psychological Record, 22(1), 1-16. doi: 10.1007/BF03394059

Galizio, M. (1979). Contingency - shaped and rule governed behavior: Instructional control of human loss avoidance. Journal of the Experimental Analysis of Behavior, 31(1), 53-70. doi: 10.1901/ jeab.1979.31-53

Guedes, M. L. (1993). Equívocos da terapia comportamental. Temas em psicologia, 1(2), 81-85.

Guedes, M. L. (1997). O comportamento governado por regras na prática clínica. Em Banaco, R. A. (Org.). (1997). Sobre comportamento e cognição: Vol. 1. Aspectos teóricos, metodológicos e de formação em análise do comportamento e terapia cognitivista (pp. 138-143). Santo Andre, SP: ESETec Editores Associados.
Hayes, S. C., \& Hayes, L. (1989). The verbal action of the listener as a basis for rule governance. In Hayes, S. C. (Ed.). Rule-governed behavior: Cognition, contingencies, and instructional control (pp. 153-188). New York: Plenum Press.

Hayes, S. C., Zettle, R. D., \& Rosenfarb, I. (1989). The verbal action of the listener as a basis for rule governance. In Hayes, S. C. (Ed.). Rulegoverned behavior: Cognition, contingencies, and instructional control (pp. 191-220). New York: Plenum Press.

Kohlenberg, R. J., \& Tsai, M. (1991/2001). Psicoterapia Analítica Funcional: Criando relações terapêuticas intensas e curativas. F. Conte, \& cols. (trads.). Santo André: ESETec.

Kroger-Costa, A., \& Abreu-Rodrigues, J. (2012). Effects of historical and social variables on instruction following. The Psychological Record, 62(4), 691-706. doi: 10.1007/BF03395829

Leonardi, J. L. (2017). Reflexões sobre a terapia analítico-comportamental no contexto da prática baseada em evidências e possibilidades de atuação em análise do comportamento clínica. Acta Comportamentalia, 25(2), 215-230.

Lettieri, D. (2017). Efeito do questionamento reflexivo sobre a emissão de autorregras e sobre a correspondência verbal em um jogo de cartas. (Dissertação de mestrado). UniCEUB, Brasília. Lloyd, K. E. (2002). A review of correspondence training: suggestions for a revival. The Behavior Analyst, 25, 57-73. doi: 10.1007/BF03392045

Matos, M. A. (2001). Comportamento governado por regras. Revista brasileira de terapia comportamental e cognitiva, 3(2), 51-66. doi:10.31505/ rbtcc.v3i2.135

Matthews, B. A., Catania, A. C., \& Shimoff, E. (1985). Effects of uninstructed verbal behavior on nonverbal responding: Contingency descriptions versus performance descriptions. Journal of the Experimental Analysis of Behavior, 43(2), 155-164. doi:10.1901/jeab.1985.43-155

Medeiros, C. A., \& Medeiros, N. N. F. A. (2012). Psicoterapia Comportamental Pragmática. Em C. V. B. B. Pessoa, C. E. Costa \& M. F. Benvenuti (Orgs.), Comportamento em Foco, v. 01 (pp. 417-436). São Paulo: ABPMC.

Medeiros, C. A. (2002a). Análise funcional do comportamento verbal na clínica comportamen- 
tal. Em A. M. S. Teixeira, A. M. Lé SénéchalMachado, J. M. dos S. de Castro \& S. D. Cirino (Orgs.), Ciência do comportamento: Conhecer e avançar, v. 2 (pp. 176-187). Santo André: ESETec.

Medeiros, C. A. (2002b). Comportamento verbal na terapia analítico-comportamental. Revista Brasileira de Terapia Comportamental e Cognitiva, 4, 105-118. doi: 10.31505/rbtcc. $\mathrm{v} 4 \mathrm{i} 2.110$

Medeiros, C. A. (2010). Comportamento governado por regras na clínica comportamental: algumas considerações. Em A. K. C. R. de-Farias (Org.), Análise Comportamental Clínica: Aspectos teóricos e estudos de caso (pp. 95-111). Porto Alegre: ArtMed.

Medeiros, C. A. (2018). Psicoterapia Comportamental Pragmática aplicada a um caso de dor de cabeça crônica. Em A. K. C. de Farias, F. N. Fonseca, \& L. B. Nery (Orgs.). Terapia e formulação de casos em Análise Comportamental Clínica (pp. 387-404). Porto Alegre: ArtMed.

Medeiros, C. A., Oliveira, J. A., \& Silva, C. O. (2013). Correspondência verbal em situação lúdica: Efeito da probabilidade de checagem. Revista Fragmentos de Cultura, 23, 563-578. doi: 10.18224/frag.v23i4.2987

Medeiros, N. N. F. A., \& Medeiros, C. A. (2018). Correspondência verbal na Terapia Analítica Comportamental: contribuições da pesquisa básica. Revista Brasileira de Terapia Comportamental e Cognitiva, 20(1), 40-57. doi: 10.31505/rbtcc.v20i1.1136

Medeiros, R. M. (2016). O efeito do reforçamento diferencial e questionamento reflexivo sobre o tema do comportamento verbal. (Monografia de Conclusão do curso de Graduação). UniCEUB, Brasília.

Meyer, S. B. (2005). Regras e auto-regras no laboratório e na clínica. Em J. Abreu-Rodrigues, \& M. R. Ribeiro (Orgs.), Análise do comportamento: Pesquisa, teoria e aplicação (pp. 211-227). Porto Alegre: Artes Médicas.

Meyer, S., \& Donadone, J. (2002). O emprego da orientação por terapeutas comportamentais. Revista Brasileira de Terapia Comportamental e Cognitiva, 4(2), 79-90. doi: https://doi. org/10.31505/rbtcc.v4i2.108
Monteles, K. M. C., Paracampo, C. C. P., \& Albuquerque, L. C. D. (2006). Efeitos de uma história de reforço contínuo e de conseqüências sociais sobre o seguir regras. Psicologia: Reflexão e Crítica, 19(2), 186-196. doi: 10.1590/ S0102-79722006000200004

Oliveira, V. L. D., \& Albuquerque, L. C. D. (2007). Efeitos de histórias experimentais e de esquemas de reforço sobre o seguir regras. Psicologia Teoria e Pesquisa, 23(2). 217-228.

Paracampo, C. C. P., \& Albuquerque, L. C. (2004). Análise do papel das consequências programadas no seguimento de regras. Interação em Psicologia, 8, 237-245. doi: 10.5380/psi.v8i2.3259

Paracampo, C. C. P., \& de Albuquerque, L. C. (2005). Comportamento controlado por regras: revisão crítica de proposições conceituais e resultados experimentais. Interação em psicologia, 9(2), 227-237. doi: 10.5380/psi.v9i2.4798

Pergher, N. K. (2002). É possível saber se o cliente está falando a verdade? Em Teixeira, A. M. S., Machado, A. M. L. S., Castro, N. M. S., Cirino, S. D. (Orgs.), Ciência do Comportamento: Conhecer e Avançar (Vol. 2, pp. 109-122). Santo André: ESETec - Editores Associados.

Peterson, N. M. (1978). An introduction to verbal behavior. Grand Rapids, MI: Behavior Associates.

Poppen, R. L. (1989). Some clinical implications of rule-governed behavior. In S. Hayes (Org.), Rule-governed behavior: Cognition, contingences, and instructional control (pp. 325-357). New York: Plenum Press. doi: 10.1007/978-1-4757-0447-1_9

Rodrigues-Ribeiro, M. R. (2001). Terapia analítico-comportamental. Em Guilhardi, H. J, Madi, M. B. B. P, Queiroz, P. P., \& Scoz, M. C. (Orgs.). (2001). Sobre comportamento e cognição: Expondo a variabilidade, (Vol. 8, pp. 99-105). Santo André: Esetec.

Schlinger, H. D., \& Blakely, E. (1987). Functionaltering effects of contingency specifying stimuli. The Behavior Analyst, 10, 41-45.

Shimoff, E., Matthews, B. A., \& Catania, A. C. (1986). Human operant performance: Sensitivity and pseudosensitivity to contingencies. Journal of the Experimental Analysis of Behavior, 46(2), 149157. doi: 10.1901/jeab.1986.46-149 
Skinner, B. F. (1953). Science and human behavior. New York: The Macmillan.

Skinner, B. F. (1957). Verbal behavior. New York: Appleton-Century-Crofts.

Skinner, B. F. (1969). Contingencies of reinforcement. New York: AppletonCentury-Crofts.

Skinner, B. F. (1974). About behaviorism. New York: Alfred A. Knopf Company

Skinner, B. F. (1989). Recent issues in the analysis of behavior. Columbus: Merril Publising Company.

Souza, A. P. S. Medeiros, C. A. Aragão, M. O. F. Medeiros, F. H., \& Azevedo, A. P. (2012). Regras versus autorregras: Que tipos de regras é mais eficaz na modificação do comportamento? Em C. V. B. B. Pessoa, C. E. Costa \& M. F. Benvenuti. Comportamento em Foco, v. 01. (Vol. 1, pp. 631-644). São Paulo: Associação Brasileira de Psicologia e Medicina Comportamental ABPMC.

Zamignani, D., \& Meyer, S. (2017). Comportamentos verbais do terapeuta no sistema multidimensional para a categorização de comportamentos na interação terapêutica (SiMCCIT). Perspectivas em Análise do Comportamento, 2(1), 25-45. doi: 10.18761/perspectivas.v2i1.47

Zettle, R. D., \& Hayes, S. C. (1982). Rule governed behavior: A potential theoretical framework for cognitive therapy. In P. C. Kendall (Ed.), Advances in cognitive-behavioral research and therapy (pp. 73-118). New York: Academic

\section{Informações do Artigo}

Histórico do artigo:

Submetido em: 18/09/2018

Primeira decisão editorial: 06/03/2019

Versão definitiva aceita em: 11/04/2019

Editor Associado: Denis Roberto Zamignani 